\title{
CVAR-BASED FORMULATION AND APPROXIMATION METHOD FOR A CLASS OF STOCHASTIC VARIATIONAL INEQUALITY PROBLEMS
}

\author{
HUI-QIANG MA AND NAN-JING HUANG
}

\begin{abstract}
In this paper, we consider CVaR-based formulation and approximation method proposed by Chen and Lin [5] for a class of stochastic variational inequality problems (for short, SVIP). Different from the work mentioned above, we regard the regularized gap function for SVIP as a loss function for SVIPs and obtain a restrained deterministic minimization reformulation for SVIPs. We show that the reformulation is a convex program for a wider class of SVIPs than that in [5]. Furthermore, by using the smoothing techniques and Monte Carlo method, we get an approximation problem of the minimization reformulation and consider the convergence of optimal solutions and stationary points of the approximation problems. Finally we apply our proposed model to solve the migration equilibrium problem under uncertainty.
\end{abstract}

Mathematics subject classification (2010): 90C33, 90C15.

Keywords and phrases: Stochastic variational inequality, conditional value-at-risk, regularized gap function, Monte Carlo sampling approximation, convergence, migration equilibrium problem.

\section{REFERENCES}

[1] R. P. Agdeppa, N. Yamashita And M. Fukushima, Convex expected residual models for stochastic affine variational inequality problems and its application to the traffic equilibrium problem, Pacific J. Optim., 6 (2010), 3-19.

[2] P. Artzner, F. Delbaen, J. M. Eber and D. Heath, Coherent measures of risk, Math. Finance, 9 (1999), 203-228.

[3] J. F. Bonnans And A. Shapiro, Perturbation Analysis of Optimization Problems, Springer, Heidelberg, 2000.

[4] X. Chen AND M. Funushima, Expected residual minimization method for stochastic linear complementarity problems, Math. Oper. Res., 30 (2005), 1022-1038.

[5] X. CHEN AND G. H. LIN, CVaR-based formulation and approximation method for Stochastic variational inequalities, Numerical Algebra, Control and Optimizationm, 1 (2011), 35-48.

[6] C. Chen AND O. L. MANGASARIAN, A class of smoothing functions for nonlinear and mixed complementarity problems, Comput. Optim. Appl., 5 (1996), 97-138.

[7] X. Chen, C. Zhang And M. Fukushima, Robust solution of monotone stochastic linear complementarity problems, Math. Program., 117 (2009), 51-80.

[8] F. H. Clarke, Optimization and Nonsmooth Analysis, Wiley, New York, 1983.

[9] R. W. Cottle, J. S. Pang And R. E. Stone, The Linear Complementarity Problem, Academic Press, New York, 1992.

[10] M. FukUshima, Merit functions for variational inequality and complementarity problems, in Nonlinear Optimization and Applications (eds. by G. Di Pillo and F. Giannessi), Plenum, New York, 1996, pp. $155-170$.

[11] M. FuKUSHIma, Equivalent differentiable optimization problems and descent methods for asymmetric variational inequality problems, Math. Program., 53 (1992), 99-110.

[12] F. FACChinei And J. S. PANG, Finite-Dimensional Variational Inequalities and Complementarity Problems, Springer, New York, 2003.

[13] H. Fang, X. Chen And M. Fukushima, Stochastic $R_{0}$ matrix linear complementarity problems, SIAM J. Optim., 18 (2007), 482-506. 
[14] P. T. HARKer AND J. S. PANG, Finite-dimensional variational inequality and nonlinear complementarity problems: A survey of theory, algorithms and applications, Math. Program., 48 (1990), $161-220$.

[15] W. W. Hogan, Energy policy models for project independence, Comput. Oper. Res., 2 (1975), 251271.

[16] W. W. Hogan, Point-to-set maps in mathematical programming, SIAM Rev., 15 (1973), 591-603.

[17] H. JIANG AND H. F. XU, Stochastic approximation approaches to the stochastic variational inequality problem, IEEE Trans. Automatic Control, 53 (2008), 1462-1475.

[18] D. Kinderlehre And G. Stampacchia, An Intruduction to Variational Inequalities and Their Aplications, Academic Press, New York, 1980.

[19] T. LARSSON AND M. PATRIKSSON, A class of gap functions for variational inequalities, Math. Program., 64 (1994), 53-79.

[20] G. H. Lin, X. Chen ANd M. Fukushima, New restricted NCP function and their applications to stochastic NCP and stochastic MPEC, Optimization, 56 (2001), 641-753.

[21] G. H. Lin And M. Fukushima, Optimality conditions and combined Monte Carlo sampling and penalty method for stochastic mathematical programs with complementarity constraints and recourse, Technical Report 2005-005, Department of Applied Mathematics and Physics, Kyoto University, 2006.

[22] G. H. Lin AND M. FuKushima, Stochastic equilibrium problems and stochastic mathematical programs with equilibrium constraints: A survey, Pacific J. Optim., 6 (2010), 455-482.

[23] G. H. Lin AND M. FukUShima, New reformulations for stochastic nonlinear complementarity peoblems, Optim. Methods Soft., 21 (2006), 551-564.

[24] C. Ling, L. QI, G. Zhou And L. CACCETTA, The SC' property of an expected residual function arising from stochastic complementarity problems, Oper. Res. Lett., 36 (2008), 456-460.

[25] M. J. Luo AND G. H. LIN, Stochastic variational inequality problems with additional constraints and their applications in supply chain network equilibria, Pacific J. Optim., 7 (2012), 263-279.

[26] M. J. Luo AND G. H. Lin, Expected residual minimization method for stochastic variational inequality problems, J. Optim. Theory Appl., 140 (2009), 103-116.

[27] M. J. LUO AND G. H. LIN, Convergence results of the ERM method for nonlinear stochastic variational inequality problems, J. Optim. Theory Appl., 142 (2009), 569-581.

[28] A. NAGURNEY, Network economics: a variational inequality approach, Kluwer Academic Publishers, Boston, 1999.

[29] H. NiederReIter, Random Number Generation and Quasi-Monte Carlo Method, SIAM, Philadelphia, 1992.

[30] J. S. PANG, Complementarity problems, Kluwer Academic Publishers, Boston, 1994.

[31] B. PAtrick (Eds), Probability and Measure, Wiley Interscience, New York, 1995.

[32] D. RALPH AND H. XU, Implicit smoothing and its application to optimization with piecewise smooth equality constrains, J. Optim. Theory Appl., 124 (2005), 673-699.

[33] R. T. RockAfellar And S. URYASEV, Optimization of conditional value-at-risk, Journal of Risk, 2 (2000), 493-517.

[34] R. T. RockAfellar AND S. URyasev, Conditional value-at-risk for general loss distributions, J. Bank. Finance, 26 (2002), 1443-1471.

[35] A. Ruszczynski And A. Shapiro (Eds), Stochastic Programming, Handbooks Oper. Res. Management Sci. 10, Elsevier, Amsterdam, 2003.

[36] A. Shapiro AND H. Fu, Stochastic mathematical programs with equilibrium constraints, modeling and sample average approximation, Optimization, 57 (2008), 395-418.

[37] D. De Wolf And Y. SMeERs, A stochastic version of a Stackelberg-Nash-Cournot equilibrium model, Manag. Sci., 43 (1997), 190-197.

[38] H. XU, Sample average approximation methods for a class of stochastic variational inequality problems, Asia-Pacific J. Oper. Res., 27 (2010), 103-119.

[39] H. XU AND D. Zhang, Smooth sample average approximation of stationary points in nonsmooth stochastic optimization and applications, Math. Program., 119 (2009), 371-401.

[40] C. ZHANG AND X. CHEN, Stochastic nonlinear complementarity problem and applications to traffic equilibrium under uncertainty, J. Optim. Theory Appl., 137 (2008), 277-295. 